\title{
BMJ Open Awareness and control of hypertension in Bangladesh: follow-up of a hypertensive cohort
}

Dewan Shamsul Alam, ${ }^{1}$ Muhammad Ashique Haider Chowdhury, ${ }^{1}$ Ali Tanweer Siddiquee, ${ }^{1}$ Shyfuddin Ahmed, ${ }^{1}$ Louis Wilhelmus Niessen ${ }^{2,3}$

To cite: Alam DS,

Chowdhury MAH,

Siddiquee A T, et al.

Awareness and control of hypertension in Bangladesh: follow-up of a hypertensive cohort. BMJ Open 2014;4: e004983. doi:10.1136/ bmjopen-2014-004983

- Prepublication history for this paper is available online To view these files please visit the journal online (http://dx.doi.org/10.1136/ bmjopen-2014-004983).

Received 2 February 2014 Revised 19 August 2014 Accepted 22 September 2014

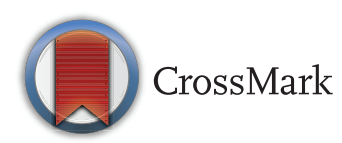

${ }^{1}$ Centre for Control of Chronic Diseases (CCCD), icddr,b, Dhaka, Bangladesh 2Johns Hopkins Bloomberg School of Public Health, Baltimore, Maryland, USA ${ }^{3}$ Liverpool School of Tropical Medicine, University of Warwick, Liverpool, UK

Correspondence to Dr Dewan Shamsul Alam; dsalam@icddrb.org

\section{ABSTRACT}

Objectives: To assess the effect of awareness and advice to seek care on blood pressure (BP) control among patients with hypertension in Bangladesh.

Design: Longitudinal study.

Setting: The study was carried out in icddr,b surveillance sites at rural Matlab in Chandpur district and semi-urban Kamalapur in Dhaka, Bangladesh.

Participants: Randomly selected men and non-pregnant women aged 20 years or older without any acute illness or history of any vascular events such as stroke or acute myocardial infarction.

Main outcome measure: Hypertension was defined as systolic BP (SBP) $\geq 140$ and/or diastolic BP (DBP) $\geq 90 \mathrm{~mm} \mathrm{Hg}$ or as self-reported hypertension under medication. We advised patients to seek care from a qualified provider and to adopt a healthy lifestyle. We compared changes in BP from baseline to follow-up at around 6 months.

Results: Overall, $17.1 \%$ ( $n=287$ ) of participants had hypertension at baseline with significantly higher prevalence in the semi-urban than in the rural population ( $23.6 \%$ vs $10.8 \%$; $p<0.001$ ); half were unaware of their condition. At follow-up, 83\% ( $\mathrm{n}=204)$ reported a visit to any healthcare provider. In the semi-urban area, a higher proportion of patients visited medically qualified practitioners than in the rural area $(76.7 \%$ vs $36.6 \%$, $p<0.000)$. SBP $(-3.3 \pm 20.7 \mathrm{~mm} \mathrm{Hg} ; \mathrm{p}<0.01)$ and DBP $(-2.0 \pm 13.0 \mathrm{~mm} \mathrm{Hg} ; p<0.02)$ were lower at follow-up. Those who visited medically qualified practitioners had significant SBP $(-3.9 \pm 22.4 \mathrm{~mm} \mathrm{Hg} ; p<0.03)$ and DBP $(-2.7 \pm 14.1 \mathrm{~mm} \mathrm{Hg} ; \mathrm{p}<0.02)$ reduction. BP reduction did not reach statistical significance among those visiting a pharmacist or their village doctors. Overall, half of the patients with hypertension achieved the BP control goal (BP<140/90 mm Hg).

Conclusions: Awareness and simple health messages increase provider visit, reduce blood pressure and improve BP control in hypertensive Bangladeshis. Longer-term follow-up is required to verify the sustainability.

\section{BACKGROUND}

Hypertension is the most widely prevalent, largely preventable risk factor for cardiovascular diseases (CVD) accounting for half of

\section{Strengths and limitations of this study}

- The results are based on a follow-up study in low-income settings after overcoming some limitations of cross-sectional studies.

- A realistic estimation of the effect of raising awareness on hypertension control in lowincome settings is put forth.

- Blood pressure reduction as a result of regression to the mean is unlikely in this study as we took multiple measurements following standardised procedure for characterising the baseline status as well as that at follow-up.

deaths due to ischaemic heart disease and stroke. ${ }^{1}$ Globally, 7.6 million premature deaths annually and $6 \%$ of the global burden of disease are attributable to hypertension. ${ }^{2}$ Elevated blood pressure (BP) lower than the standard cut-off for hypertension (SBP 140/DBP $90 \mathrm{~mm} \mathrm{Hg}$ ) is also associated with increased risk of myocardial infarction, stroke and CVD. ${ }^{3}{ }^{4}$ Hypertension is a cause and consequence of chronic kidney diseases (CKD). A recent study showed prevalence of CKD among 22\% of undiagnosed hypertensive and $17 \%$ of prehypertensive participants in the USA. ${ }^{5}$ Therefore, uncontrolled hypertension has huge implications for the disease burden due to CVD and CKD.

A recent report suggests $18 \%$, or 12 million, of adults aged 25 years or older in Bangladesh suffer from hypertension with higher prevalence in the urban rather than in the rural population. ${ }^{6}$ Earlier reports also showed that $12-15 \%$ of Bangladeshis aged 20 years or older had hypertension. ${ }^{7-9}$ Low awareness is common in populations in lowincome settings including Bangladesh. ${ }^{10-12}$ Research has shown that greater awareness is associated with higher adherence to antihypertensive treatments and $\mathrm{BP}$ control. ${ }^{13} \mathrm{~A}$ study in China ${ }^{14}$ showed only $30-45 \%$ of people with hypertension were aware of their 
condition and only $8 \%$ had achieved target BP goals. However, data are scarce on care-seeking behaviour and BP target achievement after raising awareness. Despite a huge disease burden attributable to hypertension and very high rate of unawareness, it is largely an unrecognised and under-researched public health problem in Bangladesh.

So far, all studies in Bangladesh reported prevalence data on hypertension, either measured and/or selfreported. Awareness, treatment and control data from cross-sectional studies have inherent limitations, and fail to provide information on care-seeking behaviour and level of control after the gaining of awareness. In this paper, we report prevalence, awareness and control of hypertension at baseline and explore the effect of raising awareness coupled with providing health messages urging visits to healthcare providers regarding $\mathrm{BP}$ and BP goal achievement among individuals with hypertension in urban and rural Bangladesh.

\section{METHODS}

\section{Study design and population}

This longitudinal study was carried out in rural Matlab in Chandpur district and semi-urban Kamalapur in Dhaka, Bangladesh. At both sites, International Centre for Diarrhoeal Disease Research, Bangladesh (icddr,b) has its Health and Demographic Surveillance System (HDSS) in place. ${ }^{15-17}$ The study population consisted of men and non-pregnant women aged 20 years or older without acute illness or history of vascular events such as stroke or acute myocardial infarction. We selected participants at random from the HDSS databases. We replaced randomly selected individuals who were unavailable (17\% in semi-urban Kamalapur and $15 \%$ in rural Matlab) with age and sex-matched participants from the same community who were eligible but not included in the sample. Between February and August 2011, we conducted a baseline survey and identified individuals with hypertension. Very few participants declined to participate $(3.9 \%$ in Kamalapur and none in Matlab). We reported their BP status and provided simple health messages to the hypertensive individuals with emphasis on visiting a healthcare provider, possible complications if left untreated and lifestyle factors. We followed up these hypertensives and measured BP again at 4-6 month after baseline and documented history of provider visits, medication use and BP status. An informed, voluntary written consent was obtained from each participant before enrolment.

\section{Sample size}

We estimated sample size for each age group to measure prevalence within $10 \%$ precision with $80 \%$ power. As the prevalence of hypertension increases with age, we assumed the lowest prevalence of 5\% in the 20-24 years age groups and the highest $20 \%$ or higher in the 65 years or older age groups during stratum specific sample size estimation. The estimated total sample size after considering possible refusal or non-participation was 1600 participants (800 in each site).

\section{Data collection}

We collected data on socioeconomic, demographic and lifestyle factors using a structured questionnaire. Trained interviewers administered the questionnaire at participants' homes. Interviewers also measured weight, height, waist and hip circumferences following standard procedure. ${ }^{18}$ We proscribed all participants from drinking tea, coffee, or carbonated beverages, and from eating and smoking, and asked them to avoid heavy physical activity at least $30 \mathrm{~min}$ prior to $\mathrm{BP}$ measurement. We allowed $10 \mathrm{~min}$ rest before measuring BP three times at 5 min intervals on the left arm in a sitting position with the arm supported at the level of the heart using an Omron M10 digital BP machine. The first BP measurement was discarded to avoid possible anxiety effect, and the mean value of the second and third measurements was considered for systolic and diastolic BP. SBP $\geq 140 \mathrm{~mm} \mathrm{Hg}$ or DBP $\geq 90 \mathrm{~mm} \mathrm{Hg}$ or both were defined as hypertension. Participants who were on antihypertensive medications and could show or name the antihypertensive medication or produce the prescription, were considered aware and self-reported hypertensives, irrespective of their BP status at the time of measurement. Participants who had high BP according to the aforementioned criteria and who were not under any antihypertensive medication or lifestyle modification advice from any provider, were considered unaware.

\section{Health advice}

We informed all patients with hypertension about their BP status and provided them with simple health messages in the local language, Bengali. The health messages included information on risk factors for hypertension, possible risk associated with uncontrolled $\mathrm{BP}$, lifestyle and diet related issues, particularly smoking, physical activity and extra salt intake. We advised them to visit a qualified healthcare provider. A written outline was followed to deliver the health messages uniformly and adequately. However, study workers were not involved in providing any prescription or medication. Adequate training including periodic refresher training of the health workers and regular field visits by the supervisors were ensured to minimise intraindividual and interindividual inconsistency.

\section{Follow-up}

We followed up all available patients with hypertension at around 4-6 months and collected data on treatment seeking, provider visits and medication use. A study nurse or trained Health Worker measured BP using the same electronic BP monitor following the same procedure as that at baseline. The nurse or health worker did not have access to BP data collected earlier and were not aware of the purpose of the study. We considered the BP 
goal as achieved when mean value of the second and third measurements of SBP and DBP at follow-up were $<140$ and $<90 \mathrm{~mm} \mathrm{Hg}$, respectively.

\section{Data analysis}

Data were entered on a computer with built-in range and consistency check using MS Access. Descriptive data were presented as frequency and percentages for the categorical variables, and as mean and SD for the continuous variables. $\chi^{2}$ Test was used to examine the association between categorical variables. Paired $\mathrm{t}$ test was used to compare, within individuals, change in BP from baseline to follow-up. A $p$ value $<0.05$ was considered statistically significant.

\section{RESULTS}

In total, 1678 participants were interviewed and BP measured in urban Dhaka $(\mathrm{n}=825)$ and rural Matlab $(n=853)$ (figure 1). Characteristics of the study participants are presented in table 1 . On average, participants were 43 years old and $44 \%$ were males. Urban participants were younger, more educated, had higher BMI, more abdominal obesity, higher incomes and more nonmanual occupations than rural participants. However, rural participants used more chewing tobacco and consumed more extra salt.

In total, $287(17.1 \%)$ respondents were finally diagnosed as hypertensive cases (controlled-4.6\%; stage 1$8.2 \%$ and stage 2-4.3\%). Age standardised prevalence of hypertension was $14.8 \%$ (based on Bangladesh standard population as reported by the Bangladesh Bureau of Statistics 2008). The prevalence of hypertension was significantly higher in urban than in rural participants $(23.6 \%$ vs $10.8 \% ; \mathrm{p}<0.001)$. More women than men were hypertensive. At baseline, half $(49 \%)$ the total

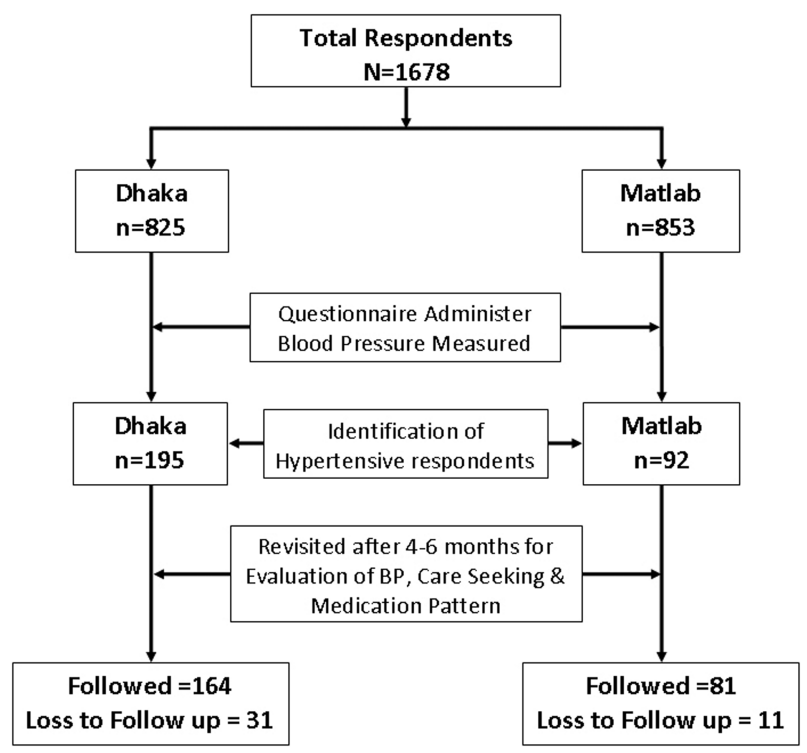

Figure 1 Study enrolment and follow-up flow diagram. BP, blood pressure. patients with hypertension were aware of their BP status and half of those who were aware $(27.2 \%)$ had their BP under control (SBP $<140$ and DBP $<90 \mathrm{~mm} \mathrm{Hg}$ ) (figure 2).

At follow-up, we were able to reach 245 (85\%) hypertensive respondents (figure 1). Of the 42 lost to follow-up, 16 had relocated, 7 refused to participate, 3 died and 16 could not be reached after repeated attempts due to their daytime work schedules. Among those available, $83.3 \%$ reported that they had visited a healthcare provider at least once after enrolment in the study (figure 3A). Over three quarters of the patients with hypertension in Dhaka and a third in Matlab visited professionally qualified doctors $(76.7 \%$ vs $36.6 \%, \mathrm{p}<0.000)$, including MBBS/MDs or more highly qualified practitioners. The rest visited drug sellers, including pharmacists, village doctors or owners of small drug outlets with or without diplomas or certificates for medical practice. This difference in choice of provider visit was significantly different between urban and rural patients with hypertension. Only about a half of those $(52.7 \%)$ who had visited a care provider could show their prescribed medication during the follow-up visit. About $28 \%$ of the patients did not receive any written prescription from their care provider.

Overall, $\beta$-blockers were the highest prescribed antihypertensive drugs either singly or in combination with calcium channel blockers followed by calcium channel blockers and angiotensin receptor blockers (figure 3B). Higher use of $\beta$-blockers was noted among those seen by rural drug sellers. Diuretics were prescribed for only about $1 \%$ of total patients. About $3 \%$ of patients received sedatives or tranquillisers although mostly in addition to antihypertensive medications.

Overall, mean SBP $(-3.3 \pm 20.7 \mathrm{~mm} \mathrm{Hg} ; \mathrm{p}<0.01)$ and DBP $(-2.0 \pm 13.0 \mathrm{~mm} \mathrm{Hg} ; \mathrm{p}<0.02)$ were significantly lower at follow-up (figure 4A, B). Those who visited professionally qualified providers had significantly lower SBP $(-3.9$ $\pm 22.4 \mathrm{~mm} \mathrm{Hg} ; \quad \mathrm{p}<0.03)$ and DBP $(-2.7 \pm 14.1 \mathrm{~mm} \mathrm{Hg}$; $\mathrm{p}<0.02)$ as compared to their baseline measure but those who visited drug sellers had no significant reduction in $\mathrm{BP}$ (figure $4 \mathrm{~A}, \mathrm{~B}$ ).

Overall, $50 \%$ of the hypertensives achieved their $\mathrm{BP}$ control goals at follow-up compared to $27 \%$ at baseline (figure 2). About $30 \%$ of uncontrolled hypertensives at baseline and $46 \%$ of newly diagnosed hypertensives achieved their BP goals at follow-up. Only $26 \%$ of the hypertensives who had their BP controlled at baseline failed to maintain it at follow-up. On the other hand, $46 \%$ of stage 1 and $33 \%$ of stage 2 hypertensives achieved their BP goals at follow-up (data not shown). BP goal achievement tended to be higher among those treated by professionally qualified practitioners than those treated by drug sellers, but the difference did not reach statistical significance. At follow-up, the proportion of hypertensive individuals who achieved BP goals were double as compared to those at baseline (figure 2). 
Table 1 Characteristics of the respondents

\begin{tabular}{|c|c|c|c|c|}
\hline & Total $n=1678$ & Dhaka $n=825$ & Matlab $n=853$ & p Value \\
\hline Age (years) & $43.5 \pm 15.1$ & $40.7 \pm 14.8$ & $46.1 \pm 15.0$ & 0.000 \\
\hline Male & $736(43.9)$ & $352(42.7)$ & $384(45.0)$ & 0.332 \\
\hline Education in years & $5.1 \pm 4.7$ & $6.2 \pm 5.1$ & $4.0 \pm 4.0$ & 0.000 \\
\hline Educational category & & & & 0.000 \\
\hline Illiterate & $582(34.7)$ & $245(29.7)$ & $337(39.5)$ & \\
\hline Primary ( $1-5$ years) & 377 (22.5) & $145(17.6)$ & $232(27.2)$ & \\
\hline Secondary (6-10 years) & $521(31.0)$ & $282(34.2)$ & $239(28.0)$ & \\
\hline Higher education (>11 years) & $198(11.8)$ & $153(18.5)$ & $45(5.3)$ & \\
\hline Occupation & & & & 0.000 \\
\hline Manual & $368(21.9)$ & $124(15.0)$ & $244(28.6)$ & \\
\hline Non-manual* & $1310(78.1)$ & 701 (85.0) & $609(71.4)$ & \\
\hline Income '000 Taka† & $15.5 \pm 13.5$ & $19.5 \pm 15.5$ & $11.6 \pm 9.9$ & 0.000 \\
\hline Income group & & & & 0.000 \\
\hline Low ( $\leq 10000$ Taka) & $846(50.4)$ & $256(31.0)$ & $590(69.2)$ & \\
\hline Middle (10 001-30 000 Taka) & $710(42.3)$ & $478(57.9)$ & $232(27.2)$ & \\
\hline High $(\geq 30001$ Taka) & $122(7.3)$ & $91(11.0)$ & $31(3.6)$ & \\
\hline $\mathrm{BMl}$ in $\mathrm{kg} / \mathrm{m}^{2}$ & $22.6 \pm 7.0$ & $24.2 \pm 5.1$ & $21.0 \pm 8.1$ & 0.000 \\
\hline BMI category & & & & 0.000 \\
\hline Underweight $(<18.5$ kg/m²) & $341(20.3)$ & $92(11.2)$ & $249(29.2)$ & \\
\hline Overweight/obese $\left(\geq 25 \mathrm{~kg} / \mathrm{m}^{2}\right)$ & $424(25.3)$ & $328(39.8)$ & $96(11.3)$ & \\
\hline Waist circumference in $\mathrm{cm}$ & $77.4 \pm 11.7$ & $81.0 \pm 12.2$ & $73.9 \pm 10.1$ & 0.000 \\
\hline Abdominal obesity ${ }^{\ddagger}$ & $466(27.8)$ & $317(38.4)$ & $149(17.5)$ & 0.000 \\
\hline Extra salt intake (at least once a day) $)^{\S}$ & $1345(80.4)$ & $564(68.5)$ & 781 (91.9) & 0.000 \\
\hline \multicolumn{5}{|l|}{ Tobacco use } \\
\hline Smokers & $500(29.8)$ & $234(28.4)$ & $266(31.2)$ & 0.207 \\
\hline Chewing tobacco & $536(31.9)$ & $203(24.6)$ & $333(39.0)$ & 0.000 \\
\hline Systolic BP & $113.1 \pm 18.7$ & $117.3 \pm 18.9$ & $109.1 \pm 17.6$ & 0.000 \\
\hline Diastolic BP & $71.6 \pm 15.7$ & $72.5 \pm 19.4$ & $70.7 \pm 10.8$ & 0.021 \\
\hline Blood pressure category & & & & 0.000 \\
\hline Normal & 1053 (62.8) & 423 (51.3) & 630 (73.9) & \\
\hline Prehypertension & $338(20.1)$ & $207(25.1)$ & $131(15.4)$ & \\
\hline Hypertension & $287(17.1)$ & $195(23.6)$ & $92(10.8)$ & \\
\hline
\end{tabular}

\section{Mean \pm SD.}

Numbers in parenthesis are percentages.

*Non-manual category included sedentary workers, professionals (eg, doctors, teachers, etc), housewives, retired persons, those unable to work and unemployed.

†Bangladesh currency Taka $80.00=\mathrm{US} \$ 1.00$

$\ddagger$ Abdominal obesity was defined as waist circumference $\geq 90 \mathrm{~cm}$ for males and $\geq 80 \mathrm{~cm}$ for females.

$\S$ Extra salt intake was referred to table salt consumption at least once a day other than salt used in cooking or food preparation.

$\mathrm{BP}$, blood pressure; BMI, body mass index.

\section{DISCUSSION}

\section{Principal findings}

This study reports the prevalence, population awareness and subsequent control of hypertension in a general population. We demonstrated that raising awareness and providing simple health messages result in high provider visits and reduction in $\mathrm{BP}$ in the Bangladeshi hypertensive population. The modest reduction in $\mathrm{BP}$ that we observed has great implications for the hypertension prevalence at population level. ${ }^{19}$ To the best of our knowledge, this is the first community-based longitudinal study in Bangladesh that followed up recently diagnosed patients with hypertension in day-to-day care settings in rural and urban communities.

We found about $88 \%$ of hypertensives who were already aware at baseline and $78 \%$ of newly diagnosed cases visited a healthcare provider at least once between baseline and follow-up. More urban patients than rural visited qualified healthcare professionals and BP reduction was significantly greater in that group. On the contrary, more rural patients $(63.4 \%)$ from all economic strata (figure 3A) visited drug sellers and the difference in BP between baseline and follow-up was not significant. It indicates the scope for training rural drug sellers on simplified hypertension management guidelines for effective utilisation of this important healthcare provider group in hypertension control in Bangladesh. Accessibility and cost may have played important roles for high drug seller visits in rural areas among all socioeconomic strata and need further exploration. Extensive use of $\beta$-blockers by both types of providers has been identified and needs to be addressed urgently. 


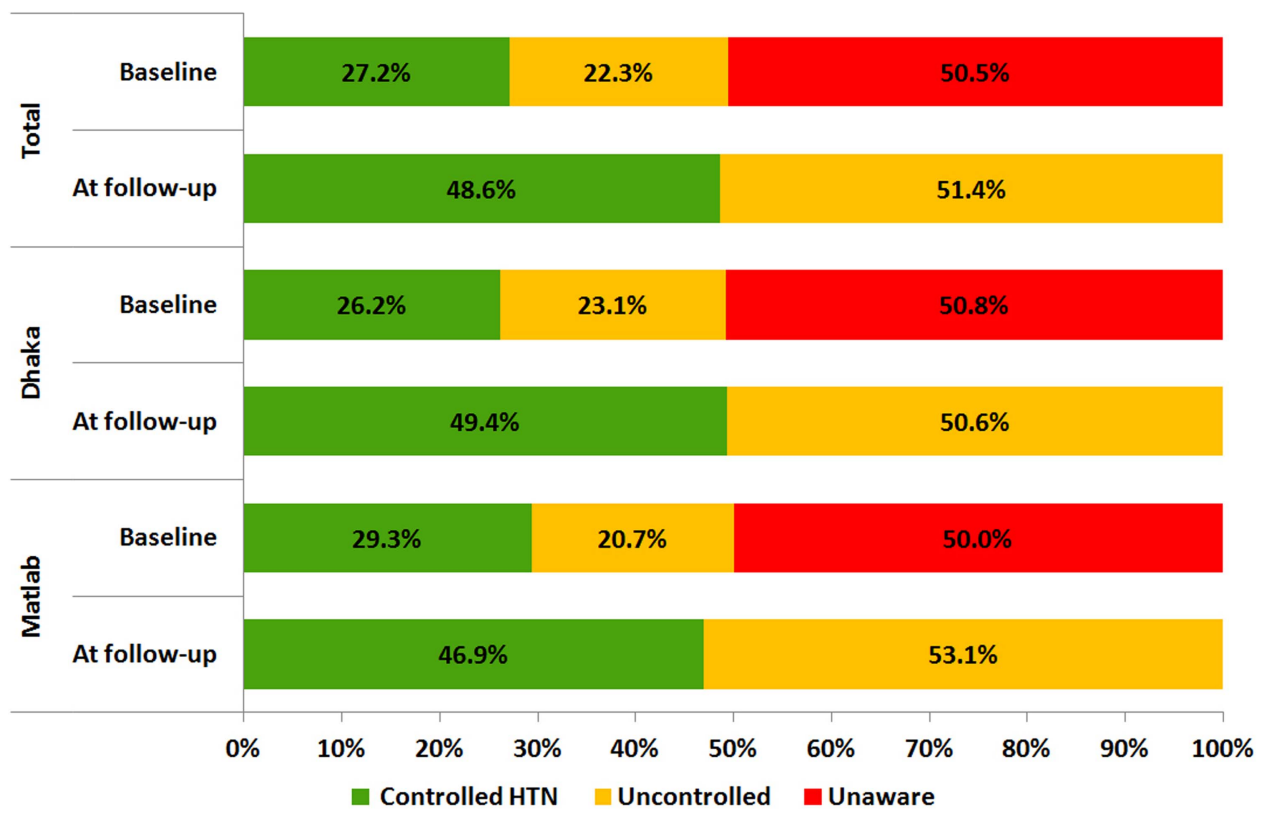

Figure 2 Distribution of awareness and control of blood pressure among patients with hypertension at baseline and at follow-up by area of residence in Bangladesh. HTN, hypertension.

Development and implementation of a simplified hypertension management guideline and training of providers may ameliorate the problem.

\section{Comparison with other studies}

Community-based data on BP levels in open populations are scarce in Bangladesh. We found higher prevalence of hypertension in urban than in rural populations. Bangladesh's Non-communicable Diseases (NCD) risk factor survey also showed higher prevalence of hypertension in urban than in rural populations $(20 \%$ vs $16 \%){ }^{6}$ The overall prevalence of hypertension in this study was $17.1 \%$ and the age adjusted prevalence was $14.5 \%$, which is fairly consistent with similar studies conducted earlier. ${ }^{6}{ }^{7}$ However, a recent systematic review of hypertension studies in Bangladesh conducted between 1994 and 2002 reported $13.5 \%$ as a pooled estimate of hypertension prevalence. ${ }^{20}$

Our study confirms other observations in similar settings, which describe a high level of unawareness among patients with hypertension in the community. ${ }^{21}{ }^{22} \mathrm{At}$ baseline, we found less than half of the patients with hypertension were aware of their $\mathrm{BP}$ status and half again of those who were aware had their BP under control. A similar pattern of poor detection and control of hypertension has been reported previously as 'the rule of halves', that is, half of the patients with hypertensive are aware and only half of those aware are treated,
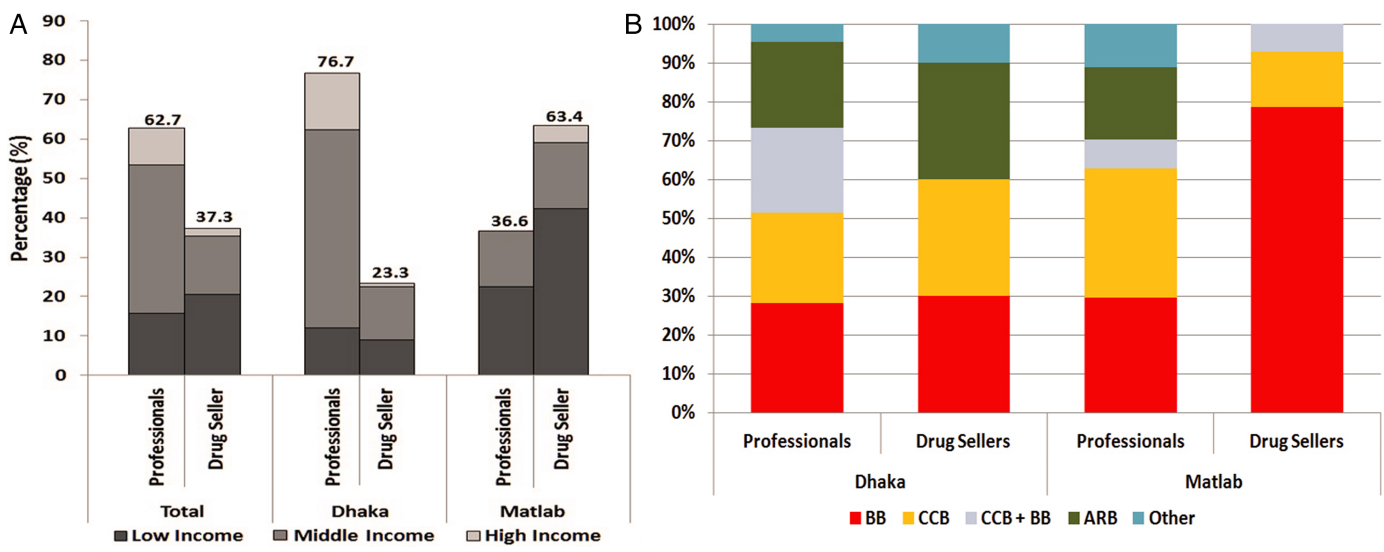

Figure 3 Pattern of health care provider visits and medication use in urban Dhaka and rural Matlab, Bangladesh. (A) Distribution of provider visits by area and economic strata. (B) Pattern of medication use by area and provider type.

*Professionals included MBBS/MD or higher educated health care providers. Drug sellers included pharmacists, village doctors or owners of small drug outlets with or without diplomas or certificates for medical practice. BB, $\beta$-blockers; CCB, calcium channel blockers; ARB, angiotensin receptor blockers. 

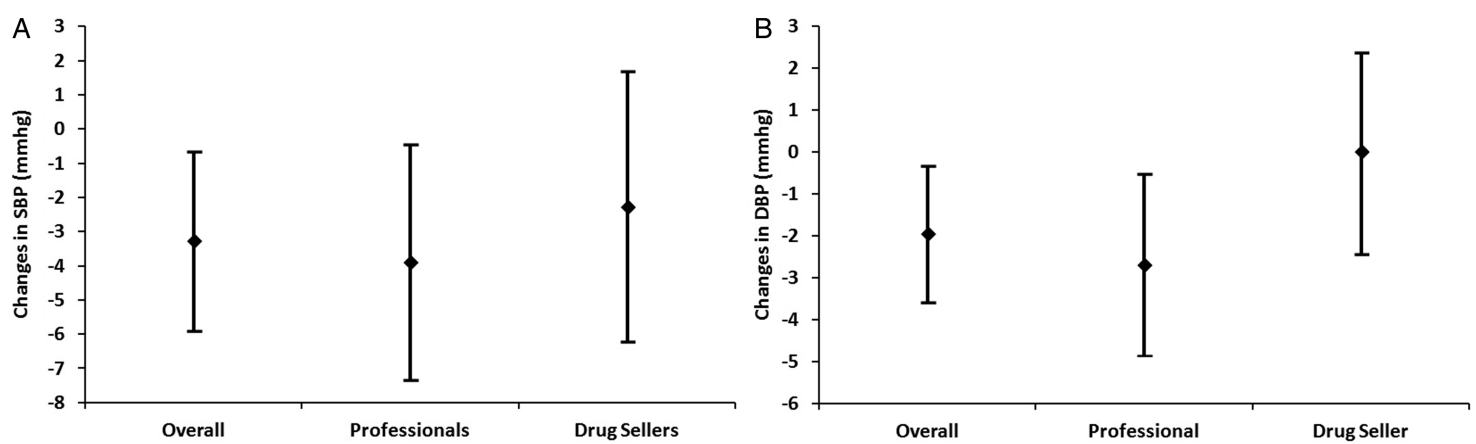

Figure 4 Change in systolic and diastolic blood pressure between baseline and follow-up by provider type. *Professionals included MBBS/MD or higher educated health care providers. Drug sellers included pharmacists, village doctors or owners of small drug outlets with or without any diplomas or certificates for medical practice. DBP, diastolic blood pressure; SBP, systolic BP.

and only half of the treated have their BP targets achieved. ${ }^{23}$ This implies that without further awarenessraising campaigns, about three quarters of all patients with hypertension in Bangladesh will continue to live with uncontrolled BP.

Our longitudinal observation indicates that better BP control can be achieved through simple communitybased efforts to raise awareness. Similar effects from raising awareness on $\mathrm{BP}$ control has been reported in different settings. ${ }^{21} 24$ These findings need a longer-term follow-up to verify sustainability. We know that multiple behavioural changes are possible and repeated intervention can be more efficacious to sustain lifestyle modifications and improve BP control. ${ }^{25} 26$ Our findings from onetime intervention indicates the scope of targeted education with regular monitoring through community health workers may result in healthier lifestyles and lower BP in the developing country context. Strengthening primary healthcare might be another option to address hypertension in resource-poor settings.

Our present findings do not focus on smoking reduction, which is known to increase risk of acute vascular events such as myocardial infarction and stroke in patients with hypertension. ${ }^{27}$ Impact of high BP is likely to be much higher in men in Bangladesh, as $50 \%$ of them are smokers as opposed to less than $2 \%$ of women. Our recent report showed that $25 \%$ of all deaths in Bangladeshi men aged 25-69 years are attributable to smoking. ${ }^{28}$ This warrants necessity for further intensification of antismoking campaigns in combination with awareness-raising to promote BP control.

We found improper antihypertensive medication prescription by qualified providers as well as drug sellers. $\beta$-Blockers were the single highest prescribed drugs, particularly by the drug sellers in rural areas, which may have implications for long-term prognosis as treatment of uncomplicated hypertension with $\beta$-blockers has been reported to be associated with increased risk of stroke without any extrabenefit for cardiovascular morbidity and mortality. ${ }^{29}$ Major hypertension management guidelines also do not recommend $\beta$-blockers as initial treatment for hypertension. ${ }^{30}$ High $\beta$-blocker prescription by rural informal practitioners was also reported by other investigators in Bangladesh. ${ }^{31}$

\section{Strengths and limitations of the study}

The major strength of our study is the population-based follow-up of hypertension control in daily settings, overcoming the limitations of concurrent evaluation of hypertension control in cross-sectional studies, which allowed for a realistic estimation of effect of a simple campaign in low-income settings.

One of the limitations of our study is that we did not have a control. As the study was conducted in two densely populated areas, it was not possible to deny some hypertensives advice or provide different information. Since we did not influence care-seeking behaviour or use of medication, the effect we observed was due to high levels of awareness and seeking care by the patients with hypertension in the community where $50 \%$ were unaware about their condition. The second issue is whether the $\mathrm{BP}$ reduction could happen anyway as a result of regression to the mean, which we believe unlikely in this study, as we took multiple measurements following standardised procedure for characterising baseline status as well as that at follow-up. Our trained workers followed the same measurement protocol and used the same equipment to ensure high-quality measurements.

Also, we did not study the actual rationale in prescribing and qualifying characteristics of the involved providers. An earlier study in Bangladesh ${ }^{31}$ reported, in detail, their findings on the qualifications and level of knowledge among non-professional healthcare providers. They found that in Bangladesh, the majority of village-level providers are certified by some authority and have some level of understanding of BP measurement and treatment, although the latter could be improved. This certainly will not be the case in many other rural and urban low-income settings. In this paper we report the modest blood lowering effect due to awareness and simple health messages at 6 months after 
baseline, but further longitudinal observation is needed to assess the effect of repeated interventions on longterm BP control, which will be reported in due course.

Our findings suggest that simple community-based efforts to raise awareness, increase diagnosing and referral advice as well as access to qualified practitioners may result in better BP control in Bangladesh and similar low-income settings. These findings also suggest the importance of developing simplified hypertension management guidelines for Bangladesh and the need for appropriate training of healthcare providers on the guidelines for management of hypertension, which are lacking at present.

\section{CONCLUSIONS}

The implications of our findings are potentially huge in two ways. First, the high level of unawareness is alarming. With an estimated 12 million patients with hypertensive in Bangladesh, ${ }^{6}$ these high levels of undiagnosed high BP will have a big impact on the total burden of stroke and ischaemic heart diseases, which are already the leading causes of adult mortality and morbidity in the country. ${ }^{32} 33$ Second, our findings of awareness, treatment-seeking behaviour and BP reduction in rural as well as urban settings in Bangladesh give cause for optimism, but need longer follow-up to verify sustainability. Drug sellers are significant healthcare providers particularly in rural settings in Bangladesh. Widening the scope to utilise them effectively through appropriate training on simplified hypertension management guidelines should be explored.

Acknowledgements The authors gratefully acknowledge the study participants and Health and Demographic Surveillance staff at the Matlab and Kamalapur sites.

Contributors All authors substantially contributed to conception and design, collection of data, or analysis and interpretation of data and critical revision of important intellectual content. DSA conceptualised the study, supervised data collection analysis and wrote the 1st draft and all redrafts. MAHC, ATS and SA were involved in data collection analysis, interpretation and revision of all drafts of the manuscript. LWN contributed to critical revising of interpretation and finalising the manuscript. All authors read and approved the final manuscript. DSA is the guarantor.

Funding This project has been funded in part with Federal funds from the National Heart, Lung, and Blood Institute, National Institutes of Health, Department of Health and Human Services, under Contract Number HHSN26820900032C and icddr,b (International Centre for Diarrhoeal Disease Research, Bangladesh). icddr,b acknowledges with gratitude the commitment of the Centre's donors for their generous support to its research efforts.

\section{Competing interests None.}

Ethics approval The study was approved by the Ethical Review Committee (ERC) of icddr,b.

\section{Provenance and peer review Not commissioned; externally peer reviewed.}

Data sharing statement Collected data as described in the methodology are available with DSA (dsalam@icddrb.org) and can be shared following icddr,b data policy (http://www.icddrb.org/who-we-are/data-policies). A detailed data set of the study will be made available for public use at the end of the contract with National Heart, Lung, and Blood Institute, National Institutes of Health, Department of Health and Human Services (https://www.nhlbighiacc.org).

Open Access This is an Open Access article distributed in accordance with the Creative Commons Attribution Non Commercial (CC BY-NC 4.0) license, which permits others to distribute, remix, adapt, build upon this work noncommercially, and license their derivative works on different terms, provided the original work is properly cited and the use is non-commercial. See: http:// creativecommons.org/licenses/by-nc/4.0/

\section{REFERENCES}

1. Kearney PM, Whelton M, Reynolds K, et al. Global burden of hypertension: analysis of worldwide data. Lancet 2005;365:217-23.

2. Lawes CMM, Hoorn SV, Rodgers A. Global burden of blood-pressure-related disease, 2001. Lancet 2008;371:1513-18.

3. Qureshi Al, Suri MF, Kirmani JF, et al. Is prehypertension a risk factor for cardiovascular diseases? Stroke 2005;36:1859-63.

4. Hsia J, Margolis KL, Eaton CB, et al. Prehypertension and cardiovascular disease risk in the women's health initiative. Circulation 2007;115:855-60.

5. Crews DC, Plantinga LC, Miller ERI, et al. Prevalence of chronic kidney disease in persons with undiagnosed or prehypertension in the United States. Hypertension 2010;55:1102-9.

6. Bangladesh Society of Medicine. Bangladesh NCD Risk Factor Survey 2010. Dhaka: Director General of Health Services, 2011.

7. Sayeed MA, Banu A, Haq JA, et al. Prevalence of hypertension in Bangladesh: effect of socioeconomic risk factor on difference between rural and urban community. Bangladesh Med Res Counc Bull 2002;28:7-18.

8. Zaman MM, Rouf MA. Prevalence of hypertension in a Bangladeshi adult population. J Hum Hypertens 1999;13:547-9.

9. Zaman MM, Yoshiike N, Rouf MA, et al. Cardiovascular risk factors: distribution and prevalence in a rural population of Bangladesh. J Cardiovasc Risk 2001;8:103-8.

10. Damasceno A, Azevedo A, Silva-Matos C, et al. Hypertension prevalence, awareness, treatment, and control in mozambique: urban/rural gap during epidemiological transition. Hypertension 2009;54:77-83.

11. Devi P, Rao M, Sigamani A, et al. Prevalence, risk factors and awareness of hypertension in India: a systematic review. $J$ Hum Hypertens 2012;27:281-7.

12. Hypertension Study Group. Prevalence, awareness, treatment and control of hypertension among the elderly in Bangladesh and India: a multicentre study. Bull World Health Organ 2001;79:490-500.

13. Hashmi SK, Afridi MB, Abbas K, et al. Factors associated with adherence to anti-hypertensive treatment in Pakistan. PLOS ONE 2007;2:e280.

14. Pang W, Li Z, Sun Z, et al. Prevalence of hypertension and associated factors among older rural adults: results from Liaoning Province, China. Med Princ Pract 2010;19:22-7.

15. Ginneken JV, Bairagi R, Francisco AD, et al. Health and demographic surveillance in Matlab: past, present, and future. Dhaka: International Centre for Diarrhoeal Disease Research, Bangladesh, 1999.

16. icddrb. Registration of health and demographic events 2011. Health and demographic surveillance system-Matlab. Dhaka, Bangladesh: International Centre for Diarrhoeal Disease Research, 2012.

17. icddrb. Kamalapur 2005-2007 census results. Dhaka, Bangladesh: International Centre for Diarrhoeal Disease Research, 2008.

18. Gibson R. Anthropometric assessment of body size. Principles of Nutritional Assessment. 2ndedn. New York: Oxford University Press, 2005:245-72.

19. Banegas JR, Rodriguez-Artalejo F, de la Cruz Troca JJ, et al. Blood pressure in Spain: distribution, awareness, control, and benefits of a reduction in average pressure. Hypertension 1998;32:998-1002.

20. Moniruzzaman, Taleb A, RahmanS, et al. Prevalence of hypertension among the Bangladeshi adult population: a meta-analysis. Reg Health Forum 2013;17:15-19.

21. Feng $X L$, Pang M, Beard J. Health system strengthening and hypertension awareness, treatment and control: data from the China Health and Retirement Longitudinal Study. Bull World Health Organ 2014;92:29-41.

22. Guessous I, Bochud M, Theler JM, et al. 1999-2009 Trends in prevalence, unawareness, treatment and control of hypertension in Geneva, Switzerland. PLOS ONE 2012;7:e39877.

23. Smith WC, Lee AJ, Crombie IK, et al. Control of blood pressure in Scotland: the rule of halves. BMJ 1990;300:981-3.

24. Ambrosio GB, Strasser T, Dowd JE, et al. Effects of interventions on community awareness and treatment of hypertension: results of a WHO study. Bull World Health Organ 1988;66:107-13.

25. Appel LJ, Champagne CM, Harsha DW, et al. Effects of comprehensive lifestyle modification on blood pressure control: main results of the PREMIER clinical trial. JAMA 2003;289:2083-93. 
26. Elmer PJ, Obarzanek E, Vollmer WM, et al. Effects of comprehensive lifestyle modification on diet, weight, physical fitness, and blood pressure control: 18-month results of a randomized trial. Ann Intern Med 2006;144:485-95.

27. Nakamura K, Barzi F, Lam TH, et al. Cigarette smoking, systolic blood pressure, and cardiovascular diseases in the Asia-Pacific region. Stroke 2008;39:1694-702.

28. Alam DS, Jha P, Ramasundarahettige $\mathrm{C}$, et al. Smoking-attributable mortality in Bangladesh: proportional mortality study. Bull World Health Organ 2013;91:757-64.

29. Bangalore S, Parkar S, Messerli FH. How useful are beta-blockers in cardiovascular disease? Anadolu Kardiyol Derg 2006;6:358-63.
30. National Clinical Guideline Centre (NCGC). Hypertension: clinical management of primary hypertension in adults (Clinical guideline 127: Update of clinical guidelines 18 and 34). London: National Clinical Guideline Centre, 2011.

31. Parr J, Lindeboom W, Khanam M, et al. Informal allopathic provider knowledge and practice regarding hypertension in urban and rural Bangladesh. PLOS ONE 2012;7:e48056.

32. Miah AH, Sutradhar SR, Ahmed S, et al. Seasonal variation in types of stroke and its common risk factors. Mymensingh Med $J$ 2012;21:13-20.

33. Uddin SN, Begum F, Malik F, et al. Coronary artery disease in young patients: clinical review and risk factor analysis. Mymensingh Med $J$ 2003;12:3-7. 